\title{
Application of Multipoint DC Voltage Control in VSC-MTDC System
}

\author{
Yang Xi, Ai Qian, Huang Jiantao, and An Yiran \\ Department of Electrical Engineering, Shanghai Jiaotong University, SEIEE 1-220, 800 Dongchuan RD, \\ Minhang District, Shanghai 200240, China
}

Correspondence should be addressed to Ai Qian; aiqian@sjtu.edu.cn

Received 4 March 2013; Revised 13 May 2013; Accepted 29 May 2013

Academic Editor: Yong Fu

Copyright (C) 2013 Yang Xi et al. This is an open access article distributed under the Creative Commons Attribution License, which permits unrestricted use, distribution, and reproduction in any medium, provided the original work is properly cited.

The voltage-source-converter- (VSC-) based multiterminal VSC-HVDC power transmission system (VSC-MTDC) is an ideal approach to connect wind farm with power grid. Analyzing the characteristics of doubly fed induction generators as well as the basic principle and the control strategy of VSC-MTDC, a multiterminal DC voltage control strategy suitable for wind farm connected with VSC-MTDC is proposed. By use of PSCAD/EMTDC, the proposed control strategy is simulated, and simulation results show that using the proposed control strategy the conversion between constant power control mode and constant DC voltage control mode can be automatically implemented; thus the DC voltage stability control and reliable power output of wind farm can be ensured after the fault-caused outage of converter station controlled by constant DC voltage and under other faults. The simulation result shows that the model can fulfill multiterminal power transmission and fast response control.

\section{Introduction}

Wind energy is one of the most widely used renewable energy sources with its large potential capacity [1]. By the end of 2012, more than 53764 installed wind power units are built in China and the installed capacity reaches 75324.2 MW [2].

But rising capacity also brings much negative influence on the grid stability and power quality [3]. With fast development of power electronic technology and voltage source converter high voltage DC transmission technology (VSCHVDC), HVDC system has been used in long distance transmission lines or cables [4]. VSCs provide continuous and independent control of real and reactive powers and have a better dynamic performance compared to current source converters [5]. The literature [6,7] points out that wind farm integration technology based on the VSC-HVDC cannot only solve the negative influence on grid safety and power quality when wind farms connect to grid, but also improve the transmission capacity, which helps to make flexible wind power flow control come true [8]. The literature [9] proposes that VSC-HVDC system enables fast control of active and reactive power independently. As mentioned above, HVDC light technology is a good way to transport bidirectional power between wind farms and grid [10]. In addition, the VSC-HVDC system can feed power into passive networks without local power generation [11].

When one terminal of the VSC-based HVDC system fails or exits, wind farm connected with single terminal will be out of operation. But the application of VSC-based multiterminal system (VSC-MTDC) characterized by high requirements on reliability and quality is able to solve the problem. VSCMTDC has lots of potential advantages compared with classic HVDC, such as short circuit current reduction and rapid control of active and reactive power [12-14]. Control strategies are studied after modeling $[15,16]$ and VSC-based MTDC has attracted much attention [17, 18], especially for wind farm integration. At present, the common used VSC-MTDC control strategies are voltage drop characteristic method [19] and master-slave method [20, 21]. But now all these strategies are still in the stage of theoretical research or simulation experiment. The literature [22] deals with power flow calculation (PFC) of hybrid AC/DC power systems where several asynchronous AC systems are interconnected via a common multiterminal VSC-HVDC system and proposes 
a unified AC-DC approach for PFC of a hybrid AC/DC power system. The literature [23] proposes a stochastic multiobjective optimization algorithm for simultaneous active and reactive power dispatch in electricity markets with wind power volatility. The literature [24] proposes a new unified method for power flow calculation in $\mathrm{AC}$ grids with embedded multiterminal HVDC systems based on voltage source converter.

\section{The Characteristics of DFIG in Wind Farm}

At present, in wind farms, variable frequency technology is the development direction, which can be divided into directly driven synchronous generator and doubly fed induction generator system according to structure and operation. Variable electrical constant frequency wind generator can realize the decoupling between rotate speed and power frequency, which helps to reduce the interaction between wind power and grid interaction. Especially double-fed induction generator (DFIG) has become the main choice in the wind farm device, as it not only changes the operation of wind power system, but also reduces the capacity of the frequency converter of wind power generation equipment. Therefore, based on the output characteristics of the DFIG, this paper studies its relationship with VSC-MTDC system coordination control. DFIG changes the input rotor excitation current frequency through the frequency converter to change the magnetic field of the rotor rotating speed. So the rotating speed is able to be a constant. At present, the control of DFIG is often made by constant output power. In such mode, active power imbalance will lead to a voltage fluctuation, which may destroy the system stability. The mission of the VSC-MTDC is to deliver power from the wind farm instantaneously to ensure the bus voltage stability. So the aim of the converter control is to keep constant AC voltage and AC active power. The gridconnected wind farm and VSC-MTDC system structure are shown in Figure 1.

\section{VSC-MTDC System and Its Control Strategy Applied in Wind Farm}

In the following part, the control strategy suitable for wind farm connected with VSC-MTDC is proposed.

3.1. Converter Station Controller Applicable to Wind Farm. In Figure 1, the system can guarantee reliable wind farm output, as well as the stability of power supply. Converterl and converter3 are connected with the power grid, converter 2 with a wind power field, and converter 4 with a passive network to provide local load. Compared with two-terminal VSCHVDC system, this system is more reliable and substantial. As mentioned previously, converter 2 controller takes the set of active power and constant AC voltage control strategy, and converter 4 connected to the passive network (VSC4) takes constant AC voltage control strategy, and converters connected to the network (VSC1 and VSC3) use multiple DC voltage control method, that is, constant DC voltage control strategy and power control strategy based on DC bias control separately. This paper uses a converter control design based on the strategy above. The active and reactive power regulation control system and DC voltage control system based on the inverse system can be simplified as shown in Figures 2 and 3.

Inside the virtual box of Figure 2 is the calculation process of inverse system. $P_{\text {sref }}, Q_{\text {sref }}$, and $E_{\text {sref }}$ are active power, reactive power, and voltage reference values and $P_{s}$, $Q_{s}, E_{s}$ are VSC output active power, reactive power, and VSC DC voltage measurement. Their differences are adjusted through proportional integral unit (PI); $M, D$ respectively for pulse width modulation depth and phase difference; $A$, $B$ as intermediate variables. The main equation (1) is shown as follows. In this paper, converter loss is ignored.

$$
\begin{gathered}
P_{s}=E_{d} I_{d}+P_{d c}, \\
A=\frac{U_{s}^{2} \cos \alpha-Q_{s}}{U_{s} Y}, \\
B=\frac{P_{s}-U_{s}^{2} Y \sin \alpha}{U_{s} Y}, \\
d=\left\{\begin{array}{l}
\arctan \left(\frac{B}{A}\right)+\alpha-\pi, \quad A \leq 0, B \geq 0, \\
\arctan \left(\frac{B}{A}\right)+\alpha+\pi, \quad A \leq 0, B \geq 0, \\
\arctan \left(\frac{B}{A}\right)+\alpha, \quad A>0, \\
M=\frac{\sqrt{2 A}}{U_{d} \cos (\delta-\alpha)} .
\end{array}\right.
\end{gathered}
$$

3.2. Multipoint DC Voltage Control. VSC1 uses a constant DC voltage control strategy shown in Figure 3, which is responsible for maintaining the balance of active power and DC voltage stability. DC voltage will rise or descend according to the direction of power flow. When the active power in VSC-MTDC system is insufficient, VSC1 sends active power to DC network by the power grid this time. When VSC1 exits, the active power in the system is insufficient, and DC voltage decreases; when the VSC-MTDC system active power is superfluous, VSC1 sends active power back to the grid. At this moment, VSC1 exits, active power in the system becomes superfluous, and DC voltage rises.

To improve the reliability of VSC-MTDC system DC voltage control, except VSC1 which uses the DC voltage control, DC voltage bias control is introduced to VSC3, that is, multipoint DC voltage control strategy based on the direct voltage deviation control. The basic principle is as follows VSC3 is in the reactive rate independent control state when VSC1 is in the normal working state; while the VSC1 occurs a fault and exits, DC voltage needs to be detected. When DC voltage exceeds the allowable range, DC voltage control will take the place of constant power control automatically, keeping active power in balance and maintaining the DC voltage constant. The control system is shown in Figure 4. 


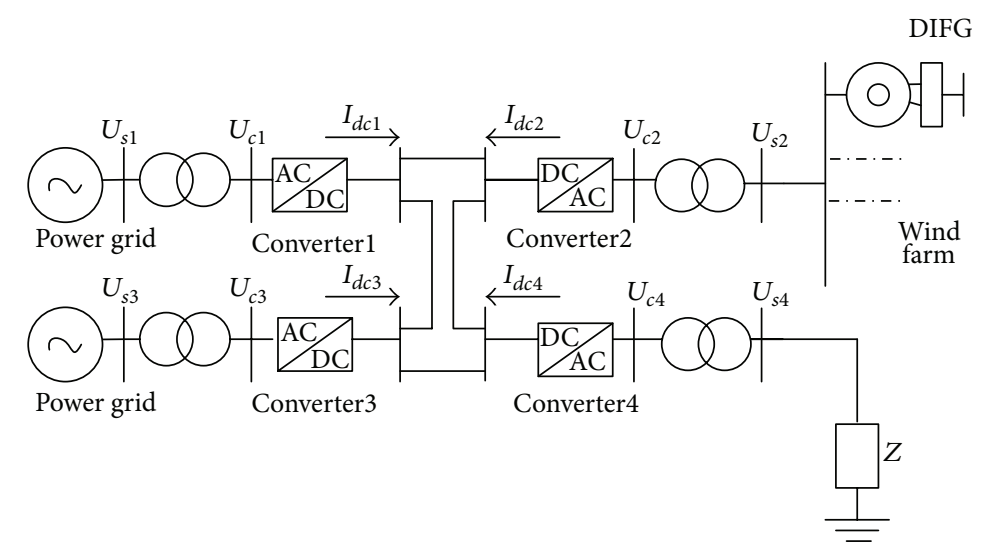

FIgURE 1: Configuration of VSC-MTDC with wind farm.

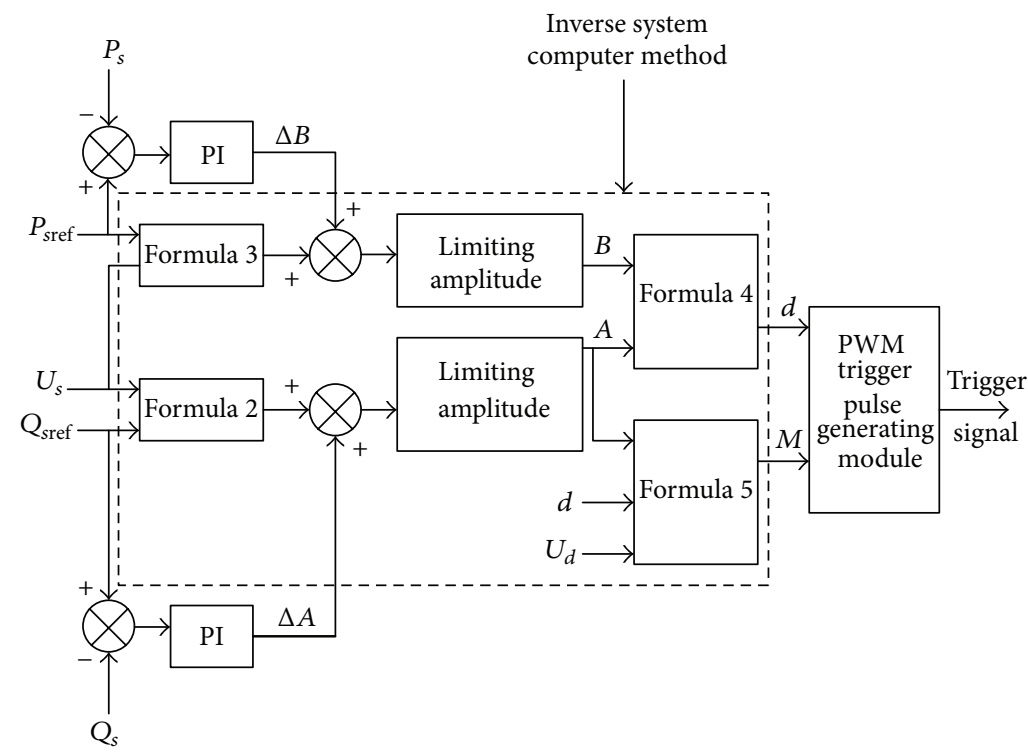

FIGURE 2: Structure of PQ control system.

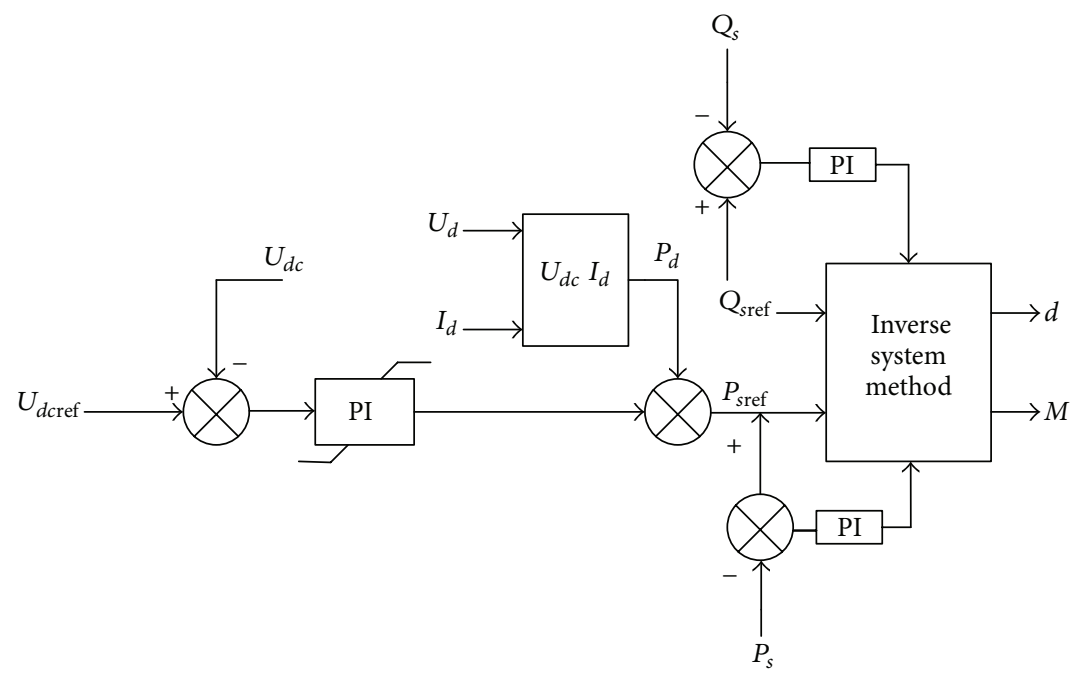

FIgURE 3: System for constant DC voltage control. 


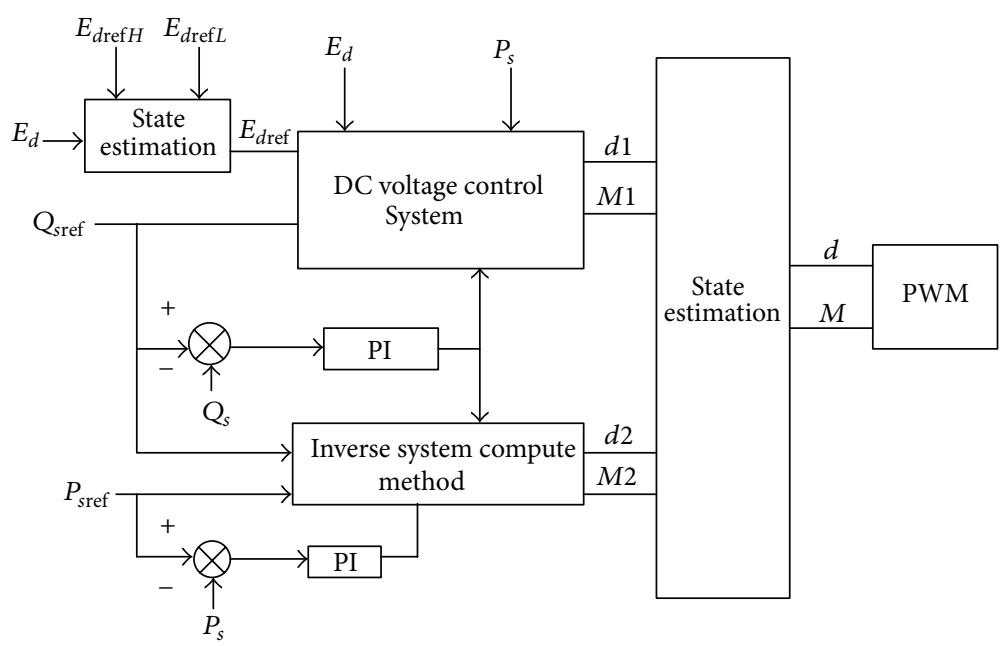

FIGURE 4: Block diagram of the DC voltage error method based on multipoint DC voltage control.

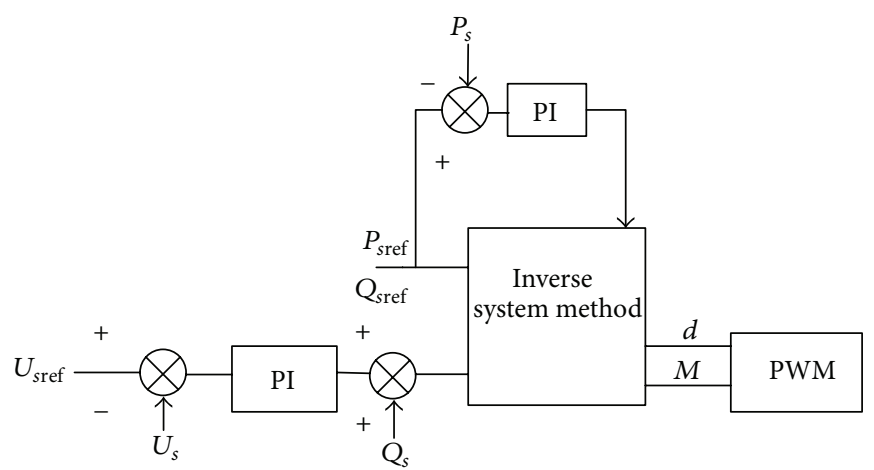

FIGURE 5: System for constant active power and constant AC voltage control.

The control system includes two controllers to achieve DC voltage and constant power control, respectively (shown in Figures 2 and 3). When VSC1 exits, if VSC1 sends active power to the grid before the fault, the DC voltage will rise; otherwise, the $\mathrm{DC}$ voltage will decrease. Once the $\mathrm{DC}$ voltage exceeds the rated DC voltage of VSC3, DC voltage reference value is fixed on the highest reference value (or the lowest reference value) and will not change. At the same time, the converter changes from fixed power control mode to constant DC voltage control mode.

3.3. Initialization of Active Power and AC Voltage Controller on Wind Farm Side. As previously mentioned, in order to keep the instantaneous power transmission from wind power and maintain the bus voltage stability of wind farm, VSC2 that is connected to the wind farm must use constant active power and AC voltage, using power independent control system (shown in Figure 2) to design the active power and constant AC voltage controller (shown in Figure 5). The reactive instruction input value is the sum of the adjusted volume of PI unit (AC voltage deviation measurements) and the measured reactive power. In Figure $5, U_{s}$ is the actual measurement of AC bus voltage value; $U_{\text {sref }}$ is bus voltage value for reference.
3.4. Passive Network Constant AC Voltage Controller. When the VSC-MTDC system supplies power to passive network, to obtain symmetrical sinusoidal alternating current, constant AC voltage control must be used to obtain the symmetry of AC voltage. The AC voltage controller is shown in Figure 6.

\section{Simulations and Analysis}

In order to verify the reliability of the strategy and applicability of VSC-MTDC in wind farm, PSCAD/EMTDC simulation software is used to build the system model as shown in Figure 1. In the system, we set the reference power at $100 \mathrm{MVA}$, the reference voltage at $62.5 \mathrm{kV}$, and the switching frequency at $1650 \mathrm{~Hz}$. In the simulation results, $U_{s n}, E_{d n}$, and $P_{s n}(n=1,2,3,4)$ are representative of each VSC connection bus AC voltage, VSC DC voltage, active power VSC into VSCMTDC system. There are some cases studied as follows.

Case 1. Simulation of wind speed change and fan switch caused by active fluctuations from wind farm. At $1 \mathrm{~s}$, active power from VSC2 to VSC-MTDC system rises from $50 \mathrm{MW}$ to $100 \mathrm{MW}$, and results are shown in Figure $7\left(U_{s 4}\right.$ is the voltage of passive network and $U_{s 2}$ is the wind farm bus voltage). The results show that the controller can track 


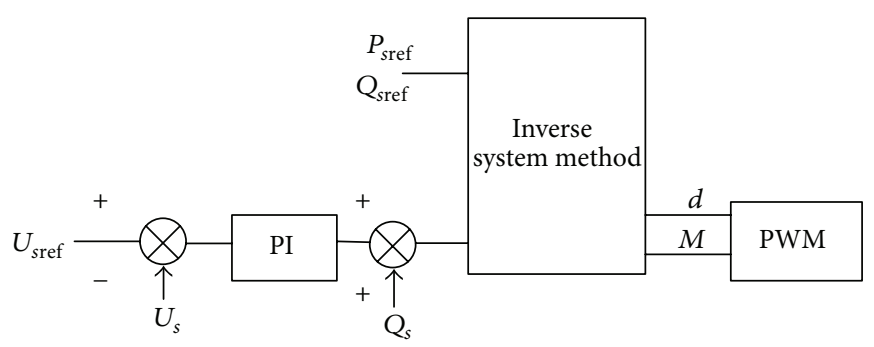

FIgURE 6: System for constant AC voltage control.

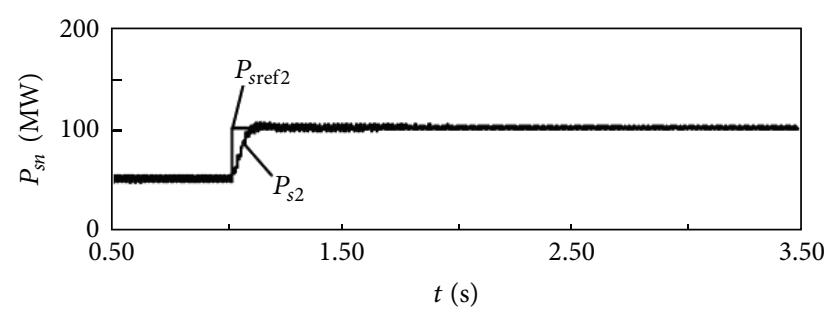

(a) Active power of VSC2

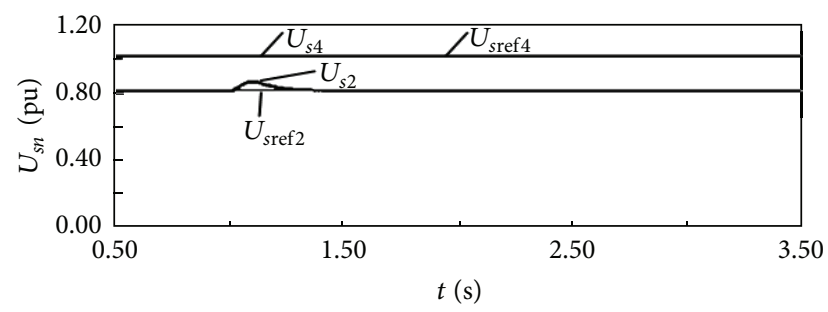

(b) AC bus voltage of VSC2 and VSC4

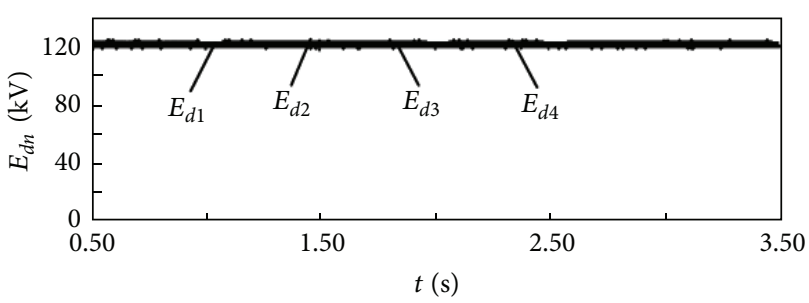

(c) DC voltage of current converter

FIGURE 7: Variation of active power in wind farm.

the wind changes well and ensure the stability of the system effectively.

Case 2. Before the fault, $P_{s 3}=300 \mathrm{MW}, P_{s 4}=-100 \mathrm{MW}$, VSC1 transmits active power to the DC network. At $1 \mathrm{~s}, \mathrm{VSC} 1$ gets a fault and exits, and DC voltage increases; VSC3 is automatically converted to DC voltage mode from constant power mode, and the DC voltage is controlled near $130 \mathrm{KV}$. The results are shown in Figure 8. It can be seen that when VSCl exits, a DC voltage is still able to remain constant and active power from the wind farm and bus voltage are stable.

Case 3. Before the fault, $P_{s 3}=200 \mathrm{MW}, P_{s 1}=150 \mathrm{MW}$, VSC1 delivers active power to the DC network. At 1s, VSC1 faults

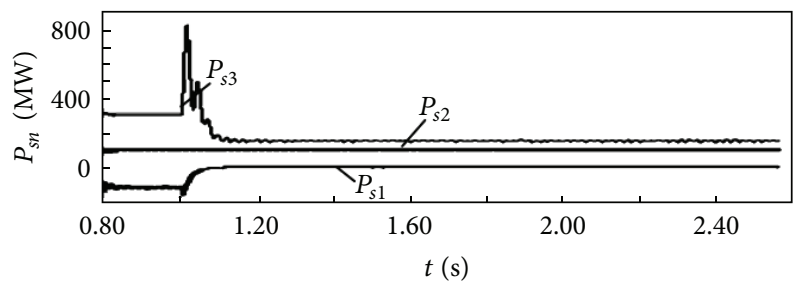

(a) Active power of VSC1-VSC3

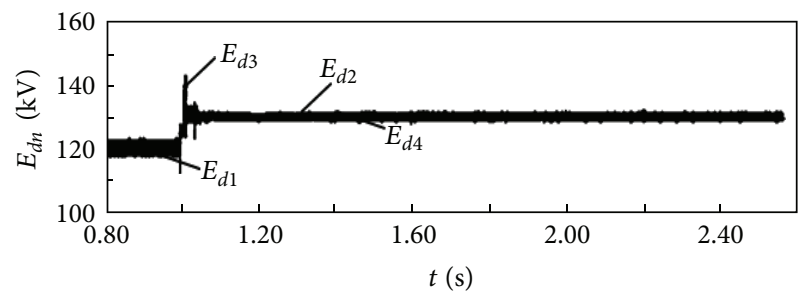

(b) DC voltage of converter

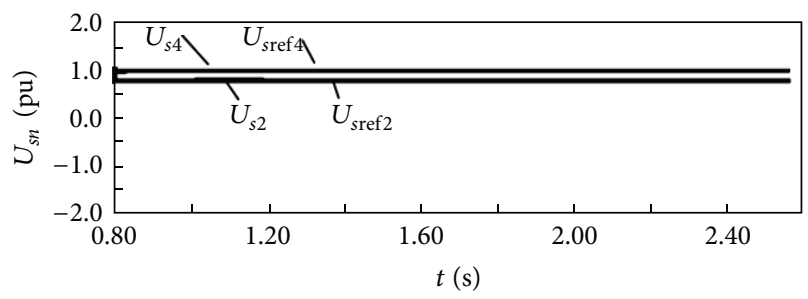

(c) AC bus voltage of VSC2 and VSC4

Figure 8: Permanent loss of VSC1 under condition of absorbing active power from DC side.

and exits, and DC voltage decreases; VSC3 is automatically converted to DC voltage mode from constant power mode, and the DC voltage is controlled near $110 \mathrm{KV}$. The results are shown in Figure 9. It can be seen from the figure that when VSC1 exits, DC voltage is still able to remain constant and active power from the wind farm and bus voltage are stable.

Case 4. One phase short circuit fault on wind farm bus automatically eliminated $100 \mathrm{~ms}$ after the fault occurs. The result is shown in Figure 10 that during the fault, VSC-MTDC can guarantee the stability of the DC voltage. When the fault disappears, the system can be quickly returned to the state before the fault. 


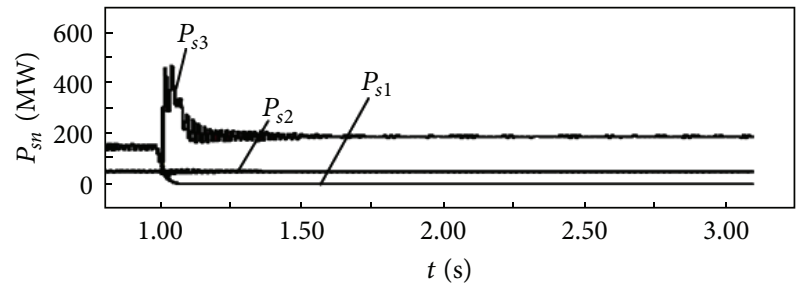

(a) Active power of VSC1, VSC2, and VSC3

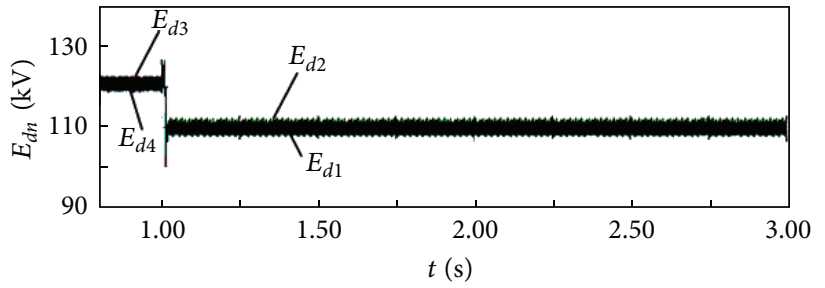

(b) DC voltage of current converter

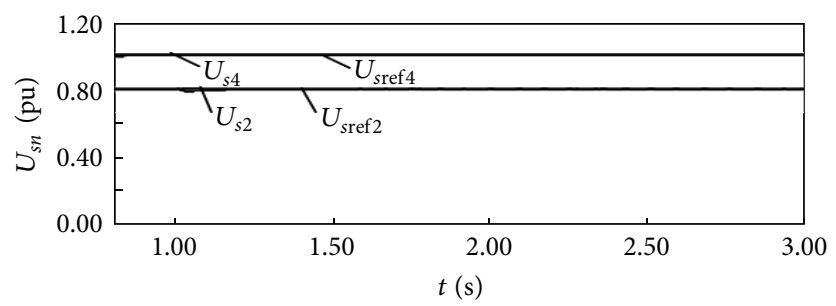

(c) AC bus voltage of VSC2 and VSC4

FIGURE 9: Permanent loss of VSC1 under condition of injecting active power into DC side.

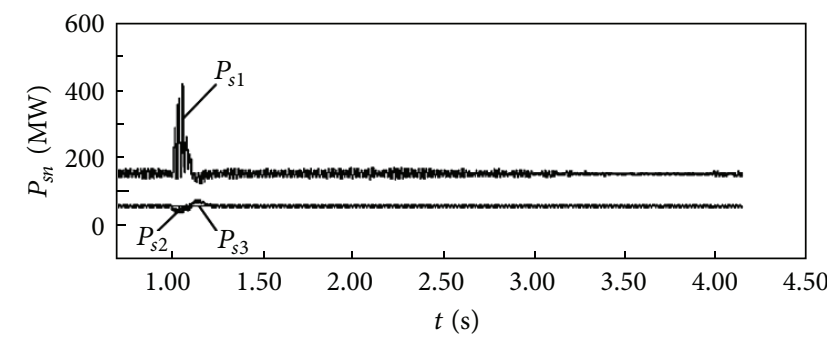

(a) Active power of VSC1, VSC2, and VSC3

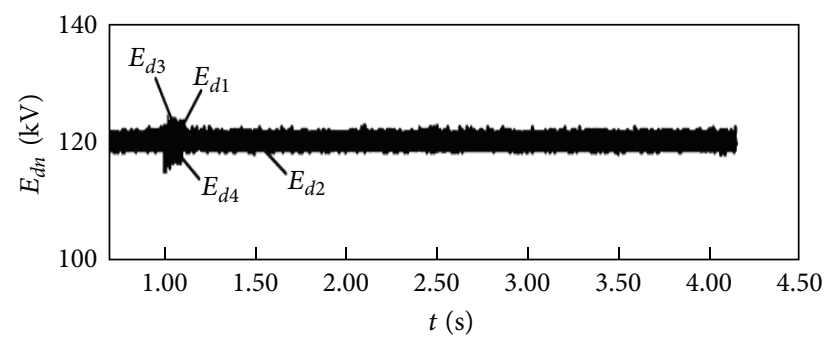

(b) DC voltage of current converter

FIGURE 10: A single line-to-ground fault on the AV bus of the wind farm.

\section{Conclusion}

Multipoint DC voltage controlled VSC-MTDC system can switch the operation mode without communication and greatly improves the operation reliability and economy. So it will be widely used in future transmission and distribution. The large disturbance between stations or communication network has little influence on the output of wind farms. One such application is to supply systems characterized by high load density and high requirements on reliability and quality together with high costs after production interruption. The next step in research will concentrate on the optimization of control strategy and coordination control between the converters.

\section{Acknowledgment}

This project is supported by the National Natural Science Foundation of China (51077092) and 863 project (2011AA5A108).

\section{References}

[1] A. Tapia, G. Tapia, J. X. Ostolaza, J. R. Saenz, R. Criado, and J. L. Berasategui, "Reactive power control of a wind farm made up with doubled fed induction generators. I," in Proceedings of the IEEE Porto Power Tech Conference, Porto, Portugal, September, 2001.

[2] "Statistics of 2012 China's installed wind power capacity," China Renewable Energy Society, vol. 3, pp. 1-3, 2013.

[3] J. Jing and A. Qian, "Evaluation of construction and operation of wind farms in China and their development prospects," East China Electric Power, vol. 35, no. 8, pp. 44-49, 2007 (Chinese).

[4] B. Anderson and C. Braker, "A new era in HVDC," IEE Review, vol. 46, no. 2, pp. 33-39, 2000.

[5] F. Yong, S. Yeleti, and S. Abdelwahed, "Optimal operation of multi-terminal VSC MVDC power distribution system," in Proceedings of the International Conference on High Voltage Engineering and Application, pp. 17-20, Shanghai, China, September 2012.

[6] K. Sobrinkkh, P. L. Sorensen, P. Cristrensen et al., "DC feeder for connection of a wind farm," in Proceedings of the CIGRE Symposium, KualaLumpur, Malaysia, 1999.

[7] K. Sobrink and P. L. Sorensen, "Feasibility study regarding integration of the 160MW wind farm using VSC transmission," in Proceedings of the CIGRE Symposium, 2001.

[8] W. Xiaoguang and T. Guangfu, "Effect of VSC-HVDC applied on improving windfarm voltage stability," Power System Technology, vol. 31, no. 8, pp. 27-31, 2007 (Chinese). 
[9] L. Weimers, "New markets need new technology," in Proceedings of the International Conference on Power System Technology (POWERCON '00), vol. 2, pp. 873-877, Perth, Australia, 2000.

[10] H.-F. Liang, G.-Y. Li, G.-K. Li, K. Zhang, and M. Zhou, "Simulation study of VSC-HVDC system connected to passive network," Power System Technology, vol. 29, no. 8, pp. 45-50, 2005 (Chinese).

[11] P. M. Meshram, A. N. Kadu, R. N. Nagpure, and K. L. Thakre, "VSC-HVDC for improvement of quality of power supply," in Proceedings of the IEEE Region 10 Conference: Analog and Digital Techniques in Electrical Engineering (TENCON '04), pp. 256259, Nagpur, India, November 2004.

[12] T. Weizhong and R. H. Lasseter, "An LVDC industrial power distribution system without central control unit," in Proceeding of 31th IEEE Annual Power Electronics Specialists Conference, vol. 2, pp. 979-984, Piscataway, NJ, USA, 2000.

[13] Z. Chao, Z. Xiaoxin, L. Ruomei et al., "Study on the steady characteristic and algorithm of power flow for VSC-HVDC," in Proceedings of the Chinese Society for Electrical Engineering (CSEE '05), vol. 25, no. 6, pp. 1-5, 2005.

[14] M. Yin, G.-Y. Li, T.-Y. Niu, G.-K. Li, H.-F. Liang, and M. Zhou, "Continuous-time state-space model of VSC-HVDC and its control strategy," in Proceedings of the Chinese Society of Electrical Engineering (CSEE '05), vol. 25, no. 18, pp. 34-39.

[15] S. Cole, J. Beerten, and R. Belmans, "Generalized dynamic VSC MTDC model for power system stability studies," IEEE Transactions on Power Systems, vol. 25, no. 3, pp. 1655-1662, 2010.

[16] C. Zheng, X. Zhou, and R. Li, "Dynamic modeling and transient simulation for VSC based HVDC in multi-machine system," in Proceedings of the International Conference on Power System Technology (POWERCON '06), Chongqing, China, October 2006.

[17] D. Van Hertem and M. Ghandhari, "Multi-terminal VSC HVDC for the European supergrid: obstacles," Renewable \& Sustainable Energy Reviews, vol. 14, no. 9, pp. 3156-3163, 2010.

[18] J. Zhu and C. Booth, "Future multi-terminal HVDC transmission systems using voltage source converters," in Proceedings of the 45th International Universities' Power Engineering Conference (UPEC '10), pp. 1-6, Cardiff, UK, September 2010.

[19] L. Weixin, Control and Application of Multi-Ternimal HVDC Based on Voltage-Source Converter, McGill University, Montreal, Canada, 2003.

[20] H. Jiang and Å. Ekström, "Multiterminal HVDC systems in urban areas of large cities," IEEE Transactions on Power Delivery, vol. 13, no. 4, pp. 1278-1284, 1998.

[21] K. Sakamoto, M. Yajima, T. Ishikawa, S. Sugimoto, T. Sato, and H. Abe, "Development of a control system for a highperformance self-commutated AC/DC converter," IEEE Transactions on Power Delivery, vol. 13, no. 1, pp. 225-232, 1998.

[22] M. Baradar, M. Ghandhari, D. Van Hertem, and A. Kargarian, "Power flow calculation of hybrid AC/DC power systems," in Proceedings of the IEEE Power and Energy Society General Meeting, Sand Diego, Calif, USA, July2012.

[23] A. Kargarian and M. Raoofat, "Stochastic reactive power market with volatility of wind power considering voltage security," Energy, vol. 36, no. 5, pp. 2565-2571, 2011.

[24] M. Baradar, M. Ghandhari, and D. Van Hertem, "VSC-HVDC in power flow calculation using unified methodology," in Proceedings of the IEEE PES Innovative Smart Grid Technologies Europe, pp. 5-7, December2011. 

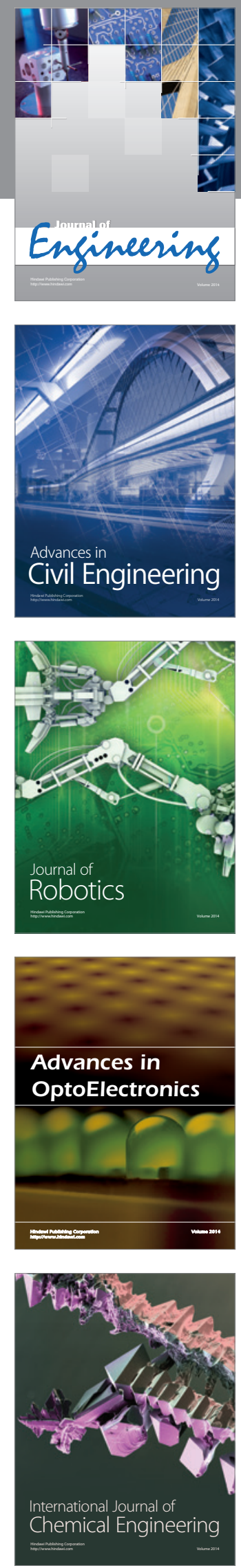

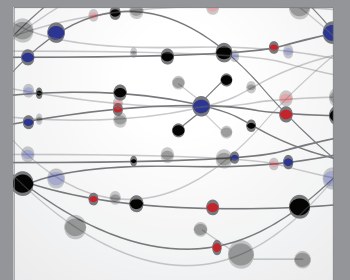

The Scientific World Journal
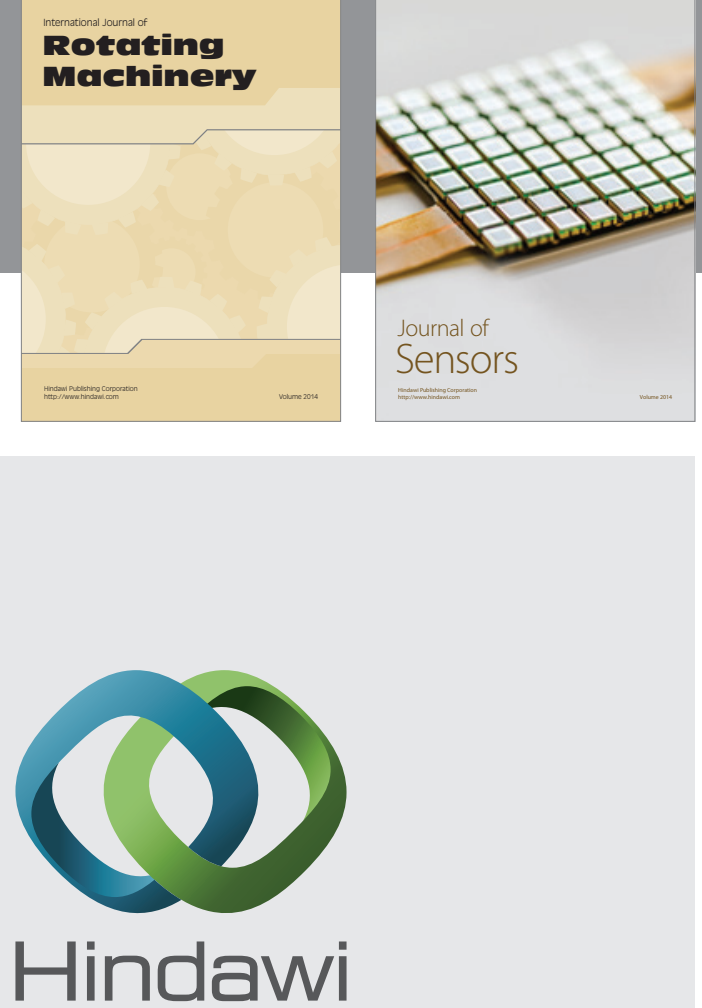

Submit your manuscripts at http://www.hindawi.com
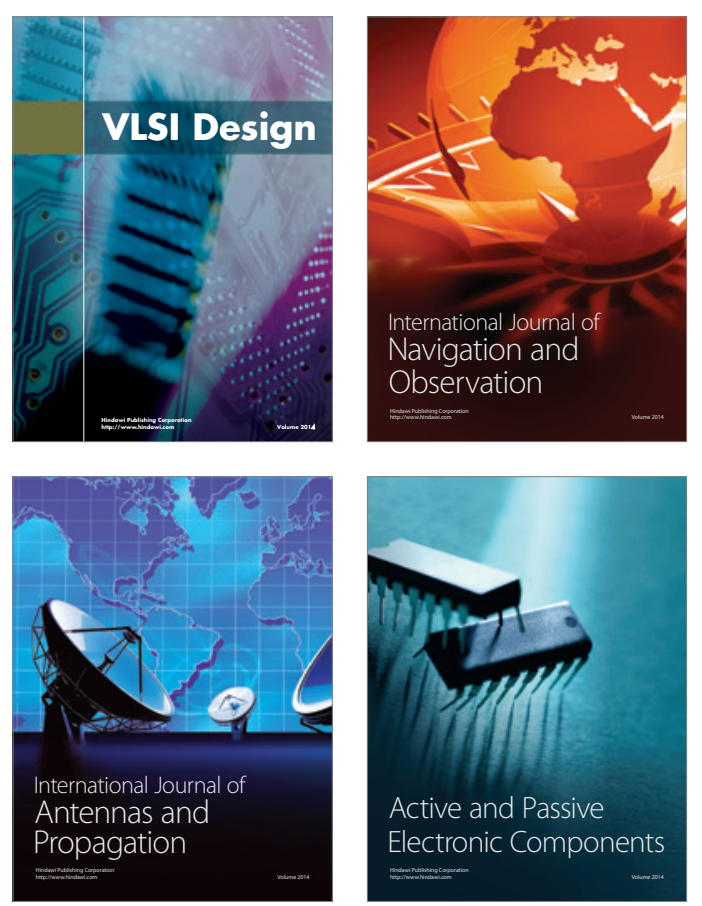
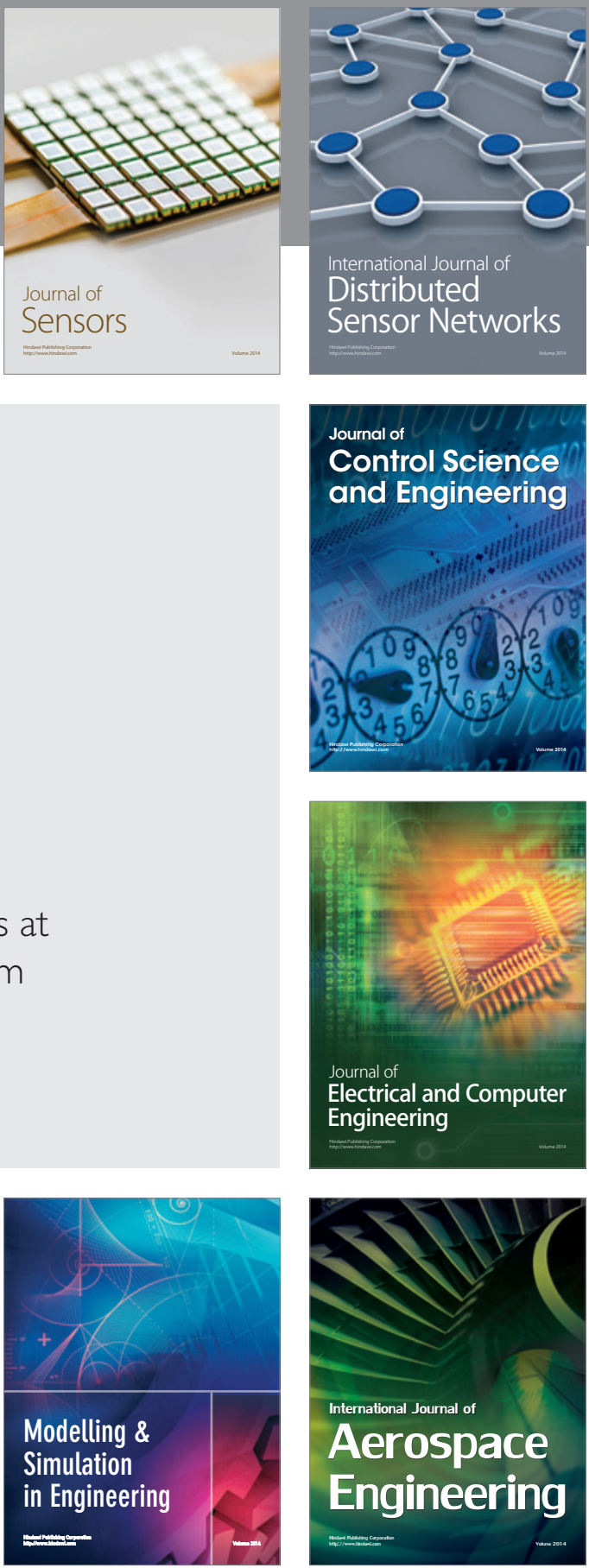

Journal of

Control Science

and Engineering
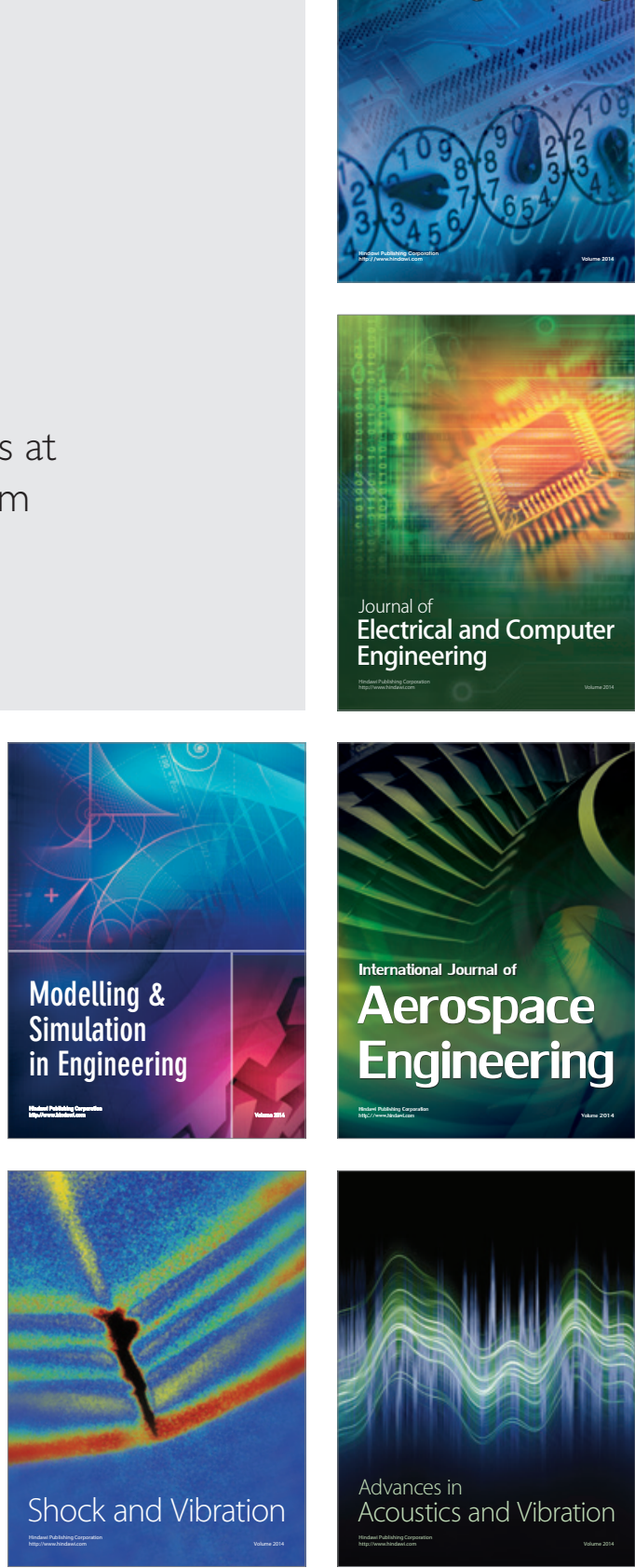